\title{
The Importance of Information in the Process of Acquisition and Usage of a Medicine for Patient Safety: A Study of the Brazilian Context
}

\author{
Patricia Lopes Fujita and Carla Galvão Spinillo \\ Postgraduate Program in Design, Federal University of Paraná, Rua General Carneiro, \\ 460, $8^{\circ}$ andar/ Curitiba / PR 80060-150, Brazil \\ patricia.fujita@gmail.com, cgspin@terra.com.br
}

\begin{abstract}
Considering the importance of oral and visual information on acquisition and use of medication, this paper discusses the outcomes of an analytical study on the cognitive load in performing the task "take a medicine" during a health treatment process (acquisition, usage and disposal of medicine) in Brazil. The task was described in a flowchart according to the steps/actions, decision points and expected outcomes to a successful performance. This allowed finding out the task informational structure during the process of taking a medicine. Then, the cognitive activities in each moment of the process were identified. The outcomes indicate the highest cognitive load occurs in the acquisition of information by patients during a health treatment process, what would affect task performance. The findings ratify the relevance of information on the process of acquisition and usage of medicines by Brazilian patients.
\end{abstract}

Keywords: Medicines, information, task analysis.

\section{Introduction}

Information transmitted through visual instructions play an important role on the use of medicines and good information is part of efficient communication between healthcare providers and patients [1]. Therefore, the success on performing a task such as 'taking a medicine' depends on the reading and understanding the information of medicine inserts (visual instructions).

The medicine insert is a printed instruction document, essential in the use of any kind of medication, providing specific information, such as: indication for medical treatment, pharmaceutical composition, warnings, and instructions of use [2].

A study conducted in England [3] suggests that patients have special interest for medicine information concerning side effects, what the medicine is for, and how to take it. However, such information may not be properly available to readers, mainly regarding its graphic presentation. This plays an important role in medicine use and in comprehension of medicine inserts by patients. Thus, graphic presentation of information is a crucial aspect for a medicine successful communication to patients [1]. 
Deficiencies in both information content and its graphic presentation in medicine inserts may lead to erroneous medicine usage. It may cause additional (or even serious/lethal) health problems to patients, such as error on the dosage, and frequency of taking a medicine [4].

Healthcare providers (e.g. doctors, pharmacists, nurses) also play an important role on the process of acquisition of a medicine by a patient, possibly providing oral and written information, contributing for patients/readers previous knowledge acquisition [5].

In a study conducted in Brazil [6], the medicine insert was considered by patients the most relevant source of information after the medical prescription and that both oral and written information acquired for the use of a medicine are chiefly important on patients healthcare education. The authors also point out that the oral information provided by doctors is insufficient, considering that during a consultation the patient may give priority to other kinds of information (e.g. diagnosis, disease) which comes prior to the medicine prescription. Further on the patient may not memorize or remember all the information given by the doctor after the consultation. Therefore, visual information can supplement and reinforce patients' knowledge about a medicine, on the cognitive and memory perspective.

\subsection{The Brazilian Medicine Context of Use}

In Brazil, in synthesis there are three general types of medicine: (a) Over the counter (medicines that can be sold to a customer/patient without a medical prescription, such as: analgesics or aspirin); (b) Medical prescription medicines (those can only be sold with medical prescription); and (b) Controlled medicines (generally distributed for free by the Brazilian government health units for patients under treatment of chronicle diseases). Those type of medicines are presented on Table 1.

Table 1. Types of medicine in Brazil

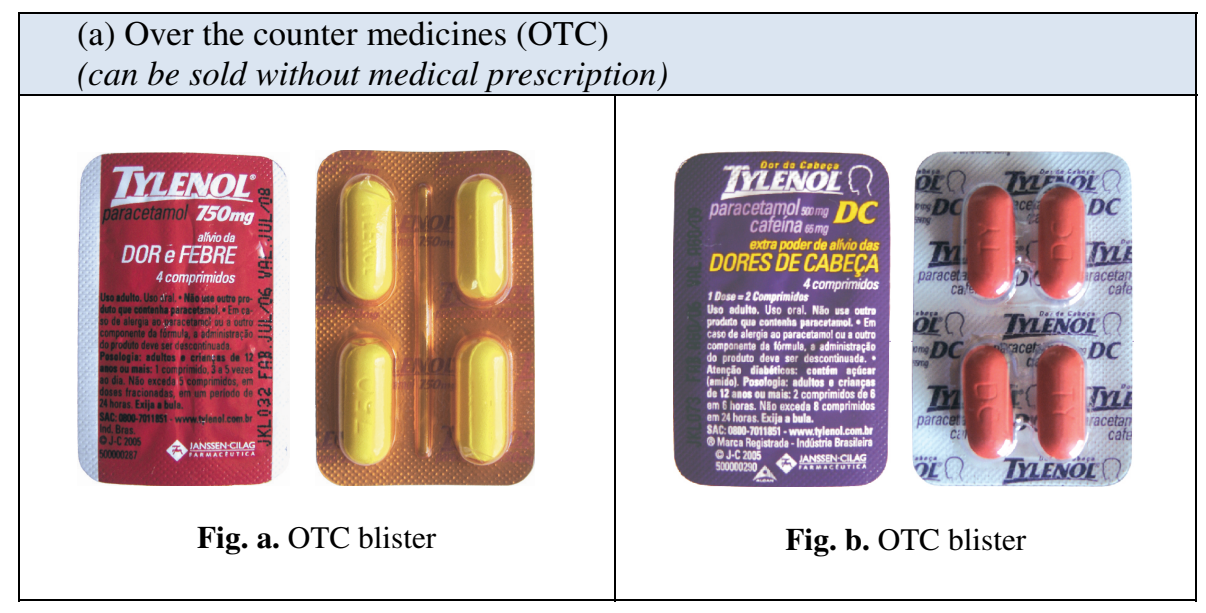


Table 1. (continued)

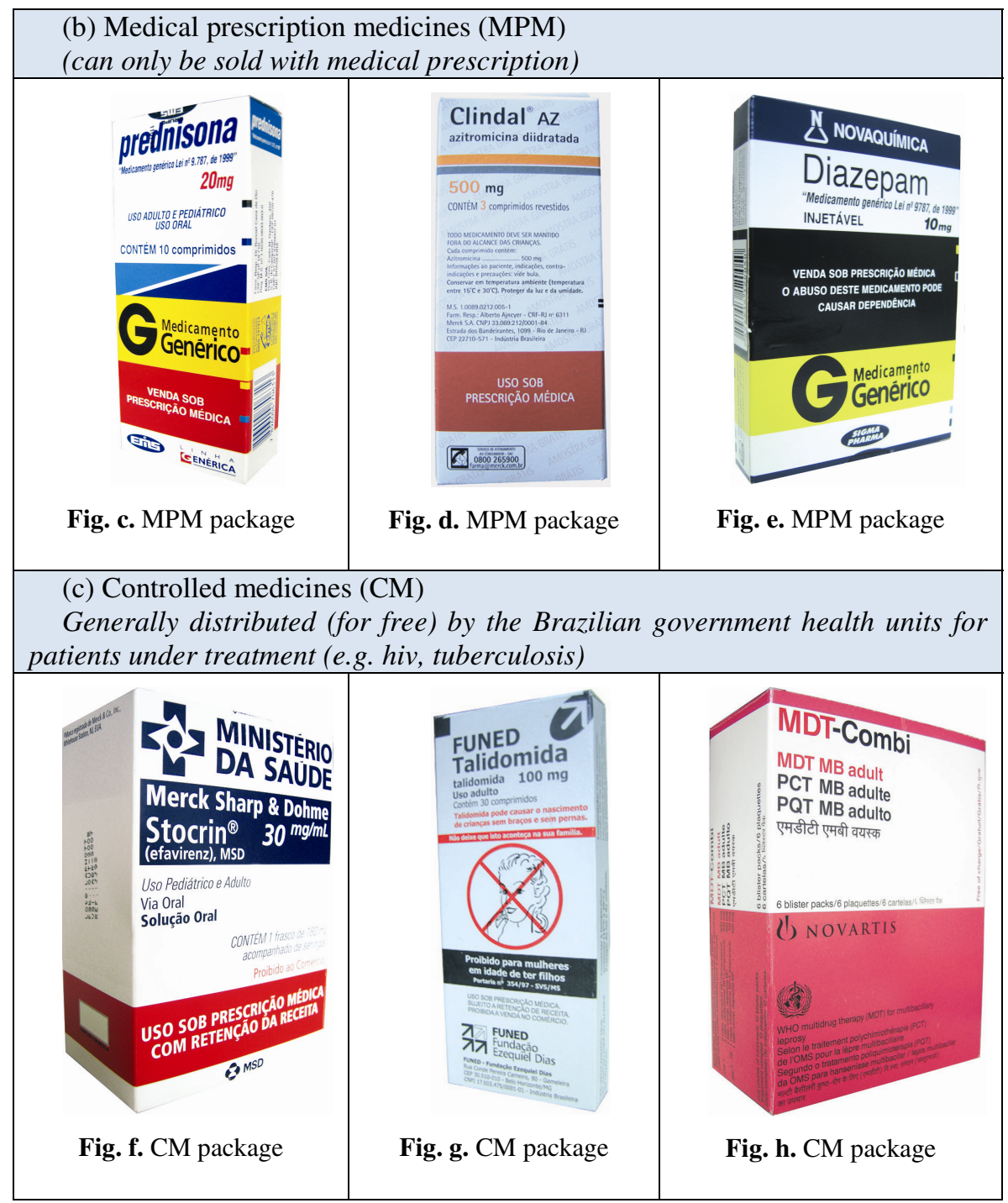

In reference to Table 1, the (a) Over the counter medicines are usually packed only in form of blisters (as presented on Figures a and b). The (b) Medical prescription and (c) Controlled medicines are packed in paper boxes as extern package and inside comes with the intern container depending on the medicine's pharmaceutical form (e.g. pills, solution). Despite the [10] Brazilian regulation stating that (b) Medical Prescription medicines can only be acquired by customers/patients presenting a document containing the medicine prescription written and signed by a doctor, many medicines of this kind are frequently sold in pharmacies without the presentation of 
any medical prescription. This fact may lead to self-medication by patients and consequently put their health at risk depending on the medicine. Although, in this case, the medicine insert is the only official source of information for the patient. This emphasizes the importance of the medicine insert as to visual information in the process of acquisition and usage of a medicine, even though medical oral information is also of large relevance to patient's education.

By taking into account the above mentioned aspects (1. Introduction and in this topic 1.1 The Brazilian medicine context of use) and considering the importance of oral and visual information on the acquisition and the use of medication, this paper presents an analysis about the demand of cognitive activity necessary to perform the task "take the medicine" according to the Brazillian context of use for a medical prescription medicine. The Analysis was made prior to the adapted diagram structured by [1] [7] Van der Waarde $(2004,2006)$ about a patient's experience during a acquisition and use of a medicine, it was developed a structure of decomposition of task analysis, proposed by [8] Moraes \& Mont'Alvão, being analyzed through the model developed by [9] Militello \& Hutton (1998), to identify which steps demand more cognitive activity load.

\section{Task Analysis of the Process of Acquisition and Usage of a Medicine by Patients in Brazil}

To provide appropriate and efficient information it is important to consider the whole process of acquisition and use of a medicine by a patient [1,7]. Thus, it demands a deeper look on the situations in which information is more relevant/significant for patients.

In order to analyze patients' actions/experience of prescribed medicines context of use, [1,7] Van der Waarde $(2004,2006)$ structured a diagram to describe the process of acquisition and use of a prescribed medicine, divided in five stages: (1) Health decision (problem); (2) Consult doctor; (3) Visit pharmacy; (4) Take the medicine; (5) Health decision (treatment results). Although this diagram focus on the regulation, social context and cultural characteristics of the European Union, it was possible to be adapted and applied to investigate the Brazilian patients' context of use, taking into account the generalized character of the mentioned steps. The Figure 1 presents the diagram adapted by the authors:

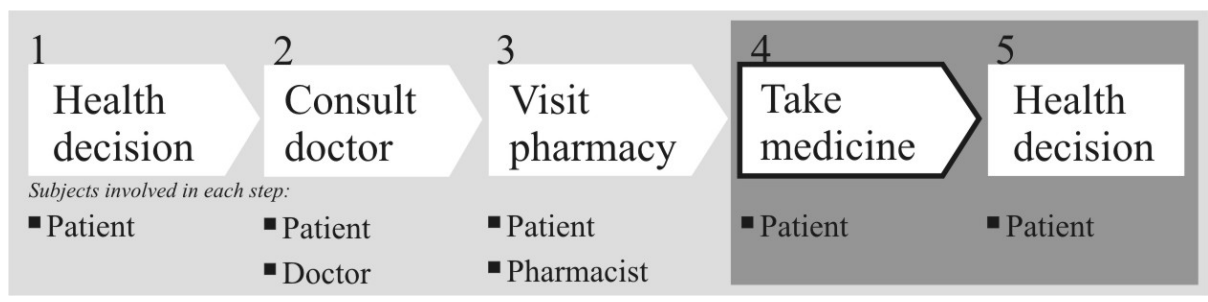

Fig. 1. Adapted diagram of the process of acquisition and use of a medicine (VAN DER WAARDE, 2004, p.85; 2006, p.41) 
In reference to Figure 1, the first step (1) Health decision (problem), initially the patient needs to recognize adversary health symptoms to make the decision of consulting a doctor. Although, according to [1,7] Van der Waarde $(2004,2006)$ this decision may vary depending on the patients' cultural, geographic, age and gender characteristics.

On the second step (2) Consult doctor (Figure 1), the patient must describe personal details and symptoms to the doctor. Based on this description the doctor will diagnose the health problem and ask for further examination, if necessary, and prescribe a medicine(s) to start a health treatment. In this step the patient has to comprehend and memorize the oral information transmitted by the doctor. After the consultation the patient will perform the third step to (3) Visit the pharmacy (Figure 1), to acquire the prescribed medicine and eventually receive oral information from the pharmacist. It is important to notice that once more the patient has to comprehend and memorize oral information.

On the fourth step (4) Take the medicine (Figure 1); initiates the process of using the medicine. Especially for this step Van der Waarde (2004, 2006), developed a subdiagram concerning four sub-steps about taking/using a medicine: (1) Open the package; (2) Consider the information; (3) Take the medicine; (4) Stop taking? (Health decision). This sub-diagram is presented and described on the next topic ('2.1 Decomposition of the task "Take the medicine" to analyze cognitive load').

On the fifth step (5) Health decision (treatment results) (Figure 1) the patient has to make a decision to stop taking the medication depending on the results/feedback on his health symptons. If more treatment is needed the patient will need to consult the doctor and therefore perform the other steps again.

\subsection{Decomposition of the Task "Take the Medicine" to Analyze Cognitive Load}

Considering the fourth step (4) Take the medicine and its sub-diagram [1,7] in order to obtain a more detailed visualization on the process of using a medicine it was developed an task representation using a task analysis decomposition model [8]. This representation characterize the task structure defining the sequence of activities necessary to perform the task "Take the medicine" correctly. The Figure 2 presents the visual representation of the task decomposition.

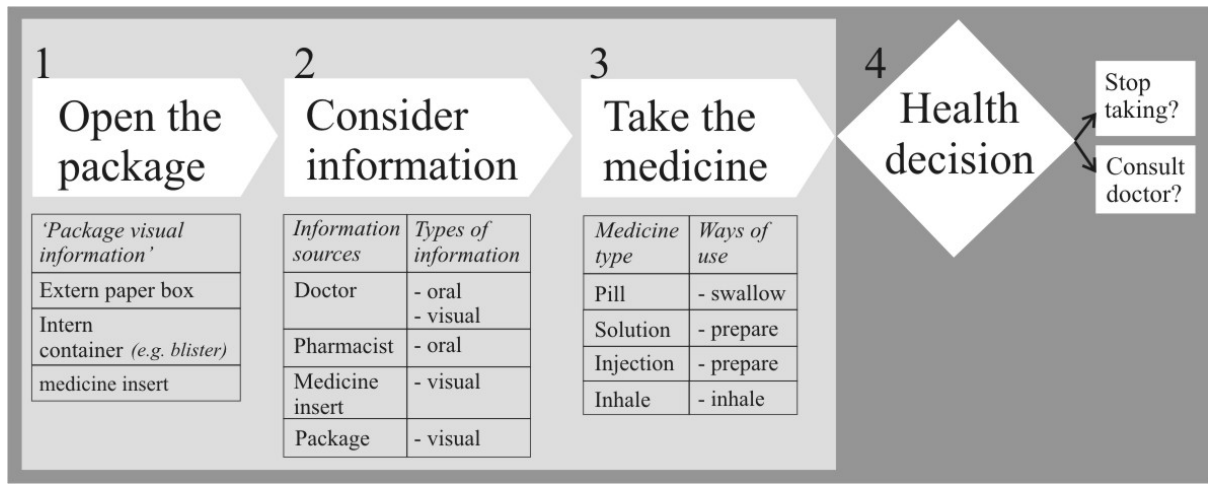

Fig. 2. Decomposition of the task "Take the medicine" 
In accordance with Figure 2, it is observed that the second sub-step (2) Consider the information involves the highest number of outputs: four different sources of information (doctor; pharmacist; medicine insert; package) to be regarded by the patient. On the third sub-step (3) Take the medicine the three options (3a. pill; $3 \mathrm{~b}$. injection; 3c. suspension) refer to possible pharmaceutical forms of a prescribed medicine.

In order to analyze and to identify the cognitive activity load necessary to use a medicine correctly based on the decomposition of the task "Take the medicine" (Figure 2) it was used the model developed by [9] Millitello and Hutton (1998). This model allows describing and identifying cognitive activity load during a task performance related to six categories: knowledge, comprehension, application, analysis, synthesis and evaluation. The Cognitive activities related to each of those categories are described on Table 2.

Table 2. Model to analyze and identify cognitive activity load [9]

\begin{tabular}{|c|c|}
\hline Categories & $\begin{array}{l}\text { Cognitive } \\
\text { activities }\end{array}$ \\
\hline Knowledge & $\begin{array}{l}\text { Acquire; Identify; } \\
\text { Recognize; Define; } \\
\text { Nominate }\end{array}$ \\
\hline Comprehension & $\begin{array}{l}\text { Explain; } \\
\text { Describe; Interpret; } \\
\text { Illustrate }\end{array}$ \\
\hline Application & $\begin{array}{l}\text { Apply; Relate; } \\
\text { Use } \\
\text { Resolve; } \\
\text { Construct }\end{array}$ \\
\hline Analysis & $\begin{array}{r}\text { Analize; } \\
\text { Categorize; } \\
\text { Compare; } \\
\text { Discriminate }\end{array}$ \\
\hline Synthesis & $\begin{array}{l}\text { Create; Project; } \\
\text { Specify; Propose } \\
\text { Develop }\end{array}$ \\
\hline Evaluation & $\begin{array}{c}\text { Validate; } \\
\text { Argument } \\
\text { Judge; } \\
\text { Recommend } \\
\text { Justify }\end{array}$ \\
\hline
\end{tabular}

According to Table 3, the presented and described categories where applied to evaluate the cognitive activities load involved to the task decomposition "Take the medicine" (Figure 2). 
Table 3. Cognitive activity during the task 'Take the medicine'

\begin{tabular}{|l|l|l|l|l|}
\hline \multirow{2}{*}{} & \multicolumn{4}{|c|}{ Task: 'Take the medicine' } \\
\cline { 2 - 5 } & $\begin{array}{l}\text { l. Open the } \\
\text { package }\end{array}$ & $\begin{array}{c}2 . \\
\text { Consider } \\
\text { information }\end{array}$ & $\begin{array}{l}\text { 3. Take } \\
\text { the } \\
\text { medicine }\end{array}$ & $\begin{array}{c}4 . \\
\text { Health } \\
\text { decision }\end{array}$ \\
\hline Categories & Cognitive activities & \multicolumn{2}{|c|}{} \\
\hline Knowledge & $\begin{array}{l}\text { Identify } \\
\text { Recognize }\end{array}$ & $\begin{array}{l}\text { Acquire } \\
\text { Identify }\end{array}$ & & \\
\hline Comprehension & & Interpret & & \\
\hline Application & & $\begin{array}{l}\text { Relate } \\
\text { Resolve }\end{array}$ & & Analize \\
& & $\begin{array}{l}\text { Analize } \\
\text { Compare }\end{array}$ & & Jompare \\
\hline Analysis & & & & Judge \\
\hline Evaluation & & & & \\
\hline
\end{tabular}

The first step (1) Open the package is the initial interaction between the patient and the medicine with its visual information located on the extern (e.g. paper box)/intern (e.g. blister or bottle) package and medicine insert leaflet. In this moment the patient conduct cognitive activity on the categorie of Knowledge, identifying and recognizing the prescribed and acquired medicine (Table 3 ).

On the second step (2) Consider information, the patient has to interpret and interrelate all the gathered information during the medicine process of acquisition. Thus, in order to process this information the patient will need to conduct the cognitive activities (presented on Table 3): Knowledge (identify and acquire information); Comprehension (interpretate the read information); Application (relate information and resolve, making decisions based on the interpreted information); Analysis (analyze and compare the acquired information).

In accord with the third step (3) Take the medicine, the patient has to be prepared to perform the task of use the medicine correctly. Although, depending on its pharmaceutical form (e.g. pill, injection, suspension) it will imply on different task performance actions (e.g. to swallow, to inject, to prepare a solution). Thereof, the considered cognitive activity on the categorie of Application (apply and usage of the medicine), presented on Table 3.

On the fourth step (4) Health decision, the patient has to evaluate effects of the medicine on his/her health (e.g. symptoms, side effects, adverse reactions); and decide if/when he/she needs to stop taking the medicine or to consult the doctor. In this concern, the performed cognitive activities will be (presented on Table 3): Analysis (analyze health/symptoms and compare) and Evaluate (judge).

\section{Conclusion and Final Considerations}

Considering the importance of oral and visual information on the process of acquisition and the use of a medicine, it was developed an analysis about the patient's 
cognitive activity load necessary to perform the task "Take the medicine", based on the Brazilian context of use.

The second described and analyzed step (2) Consider information (part of the task "Take the medicine") demanded more cognitive activity to be performed, combining the categories of: Knowledge; Comprehension; Application and Analysis. In this step (2) Consider information, the reading comprehension of information supplied on medical prescription, medicine insert and package occur in interaction with the oral memorized information provided by the doctor (during the consultation) and pharmacist (visit the pharmacy to buy the medicine). According to this outcome it is possible to infer that the processed information on this step (Consider the information) is essential for the success of the task performance "Take the medicine".

Therefore, problems on the step "Consider the information" may affect the success of the task performance and consequently compromise the treatment efficacy and patients' health. On this regard, it is ratified the importance of oral and visual information on the process of acquisition and usage of medicines by Brazilian patients.

\section{References}

1. Van der Waarde, K.: Visual information about medicines. Providing patients with relevant information. In: Spinillo, C.G., Coutinho, S.G. (eds.) Selected Readings of the Information Design International Conference 2003. Recife, SBDI I Sociedade Brasileira de Design da Informação, pp. 81-89 (2004)

2. Fujita, P.T.L., Spinillo, C.G.: Verbal Protocol as an information ergonomics tool to verify reading strategies in medicine inserts. In: AEI 2008: 2nd International Conference on Applied Ergonomics, Proceedings of the AHFE International Conference 2008, Las Vegas, Nevada, vol. 1. USA Publishing I AHFE International, Louisville (2008)

3. Dickinson, D., Raynor, T.D.K., Kennedy, J.G., Bonaccorso, S., Sturchio, J., et al.: What information do patients need about medicines? BMJ, Education and Debate 327, 861-864 (2003)

4. Fujita, P.T.L., Spinillo, C.G.: A apresentação gráfica de bula de medicamentos: um estudo sob a perspectiva da ergonomia informacional. In: Congresso Internacional de Ergonomia e Usabilidade 'ERGODESIGN, 2006, pp. 1-6. UNESP, Bauru (2006)

5. Raynor, D.K.T.: Patient compliance - the pharmacist's role. Int. Journal Pharm Practice 1, 126-135 (1992)

6. da Silva, T., Dal-Pizzol, F., Bello, C.M., et al.: Bulas de medicamentos e a informação adequada ao paciente. Revista Saúde Pública, abr. 34(2), 184-189 (2000)

7. Van Der Waarde, K.: Visual information about medicines for patients. In: Frascara, J. (ed.) Designing Effective Communications: Creating contexts for clarity and meaning, pp. 3850. Allworth Press, New York (2006)

8. Moraes, A., Mont'AlvÃO, C.: Ergonomia: conceitos e aplicações. Rio de Janeiro: 2AB (1998)

9. Militello, L.G., Hutton, R.J.B.: Applied cognitive task anlysis (ACTA): a practicioner's toolkit for understanding cognitive task demands. Ergonomics 41(11), 1628-1641 (1998)

10. Brasil. Ministério da Saúde. Resolução RDC No 140, de 29 de maio de (2003), http : / / e-legis.anvisa.gov.br/leisref/public/showAct.php?id=6311 